\title{
Therapy Made Easy
}

E-Commerce and Infrastructure in China's Psycho-Boom

\section{Hsuan-Ying}

\section{OpenEdition}

\section{Journals}

Electronic version

URL: http://journals.openedition.org/chinaperspectives/7468

ISSN: 1996-4617

\section{Publisher}

Centre d'étude français sur la Chine contemporaine

\section{Printed version}

Date of publication: 1 December 2017

Number of pages: $29-39$

ISSN: 2070-3449

\section{Electronic reference}

Hsuan-Ying, « Therapy Made Easy », China Perspectives [Online], 2017/4 | 2017, Online since 01

December 2018, connection on 28 October 2019. URL : http://journals.openedition.org/

chinaperspectives/7468

(C) All rights reserved 


\title{
Therapy Made Easy
}

\section{E-Commerce and Infrastructure in China's Psycho-Boom}

\begin{abstract}
In China, the rise of e-commerce has made significant impacts on a broad range of business and professional fields; psychotherapy, a profession born of the recent "psycho-boom" (xinli re 心理热), is one of them. This article, using materials collected from interviews, participant observation, and media accounts, delineates the development of Jiandan xinli (简单心理), a Beijing-based startup that features an e-commerce platform for psychotherapy services, and explicates how and why it has achieved enormous initial success. Drawing on the insights of anthropological studies of infrastructure, it argues that the platform can be conceptualised as an example of "infrastructural entrepreneurship," a business practice taking the construction of infrastructure—in this case, for the field of psychotherapy—as its primary mission.
\end{abstract}

KEYWORDS: e-commerce, infrastructure, 020, psychotherapy, profession.

\section{Introduction}

$\mathrm{O}$ $n$ the afternoon of 29 November 2016, like tens of thousands of people concerned about the development of psychotherapy ${ }^{(1)}$ in China, I watched a press conference being streamed live from one of Beijing's architectural landmarks, the Linked Hybrid. A report on the current state of the practice of psychotherapy in China, which was based on an extensive literature review and a survey of 5,000 clients in therapy, was released during the event-the first time this growing population had received a substantial and realistic portrait. (2) The young woman who announced these findings was not an acclaimed researcher or a leading figure in psychiatry or psychology, as might be expected. Her name was Li Zhen (李真), although she was more often known by her online alias Jian Lili (简 里里), and she was the founder and CEO of Jiandan xinlii (简单心理, literally "easy psychology"), (3) a startup company that had created an e-commerce platform for psychotherapy services. Located at the intersection of mental health and digital innovation, the company was founded in 2014 during a startup frenzy fostered by the Chinese state. Apart from Li, the event featured an impressive line-up of speakers that included Fang Xin (方新), a renowned psychologist and director of the Centre for Psychotherapy and Psychological Counselling at Peking University, and Xu Xiaoping (徐小平), a legendary entrepreneur who co-founded the education giant, New Oriental, and a principal investor in Jiandan xinli. (4)

By the time of the 2016 press conference, the platform had evolved into one of the most influential forces in Chinese psychotherapy, a field that had grown rapidly due to the so-called "psycho-boom" (xinli re 心理热). Its esteemed status was confirmed by most of the therapists I knew. They would cite as evidence the large sum of money - several million U.S. Dollarsthat the company had raised; the expanding army of therapists-around 400 - who had joined the platform; or the sheer volume of services 100,000 sessions-it had sponsored. Many therapists would compare it to other powerful institutions in the field, especially the Registry System under the Chinese Psychological Society, a professional association that had taken a leading role in the recently initiated project of professionalization. Jiandan xinli was widely considered a facilitator of this process and the most vocal advocate of professionalism. This public image resonated with the honourable vision it claimed on its website: to improve the psychotherapeutic profession and become its benchmark of excellence. ${ }^{(5)}$

Jiandan xinli is not the world's only e-commerce platform for psychotherapy services. Take the United States, for example, where in the past few years around a dozen online therapy platforms-the best known include Breakthrough, BetterHelp, Talkspace, and iTherapy—have emerged. (6) These companies, like Jiandan xinli, rely on venture capital, belong to the latest wave of digital entrepreneurship, and serve the same purpose of connecting consumers and practitioners of therapy. However, a quick comparison reveals their differences: the American platforms have the online communication channels-ranging from video conferencing to text messaging - built into their systems, a function that does not exist on Jiandan xinli. Besides this, the Chinese startup does a lot more than its American counterparts, stipulating its own standards of training and qualification, as a system of licensure is unavailable in China. It also disseminates psychological knowledge to the general public and has a prominent presence on all the major social media platforms. It has even ventured into training, setting up an institution whose programs are primarily based on online instruction. Li Zhen was clearly conscious of the sheer breadth of activities the platform has undertaken when we met in Beijing three weeks after the press conference. Reflecting

1. Two Chinese terms are associated with psychotherapy: xinli zhiliao and xinli zixun. While used as translations for "psychotherapy" and "psychological counselling," respectively, they were seen as identical and interchangeable by most therapists in China until a distinction was made by the 2013 Mental Health Law. In this article, I use "psychotherapy" as a generic term for Western-style talk therapy.

2. See Jiandan Xinli and Peking University Centre for Psychotherapy and Psychological Counselling (2016).

3. To be more precise, "Jiandan xinli" should refer specifically to the platform, which is owned by Zhujian Technology Ltd., a company founded by Li Zhen. The platform has an official English title "My Therapist." Both the company behind the platform and its English title are not well known in China, however, and in this article, I use "Jiandan xinli" to denote both the platform and the company.

4. The other three speakers were: He Feng, a veteran of Beijing's startup circles and the co-founder of Jiandan xinli; Li Songwei, an Internet celebrity with a daytime job as a counsellor at Tsinghua University; and Wei Xueman, a popular singer who had recently initiated a philanthropy program offering psychological support for single mothers.

5. See the "About Us" section of Jiandan xinli's website: http://www.jiandanxinli.com/about (accessed on 10 October 2017).

6. For a recent discussion of this trend, see Novotney (2017) 
on the exhausting months of preparation and the two-and-a-half-year e-business journey, she told me that she was often amazed by how much the company had accomplished, observing that a large part of what it had done should probably have been handled by the government or the professional associations. ${ }^{(7)}$

What does this e-commerce platform do or offer? How and why has it achieved its enormous initial success and made such a palpable impact on the field? To answer these questions, I draw on the insights of anthropological studies of infrastructure, which have grown substantially in response to the call made by the STS scholar Susan Leigh Star (1999) to study it ethnographically. ${ }^{(8)}$ Infrastructure can be broadly defined as the things that enable the normal functioning of a system. Typically taking the form of an extensive network, it exists in the background and is mostly invisible or taken for granted, except during its failures and breakdowns. Infrastructure is both "ontological and relational" (Seo 2017), both "things and also the relations between things" (Larkin 2013, p. 329). As Star (1999, p. 381) indicates, "embeddedness" is one of its essential features, and one infrastructure is "sunk into and inside of" others. Infrastructure can become fragile with wear and is thus in need of constant maintenance or updates; this inherent weakness applies to both its traditional forms - for example, electricity, water supply, roads, and railway systems - and its contemporary manifestations such as the Internet and digital platforms, of which Jiandan xinli is an example.

The main thesis of this article is that Jiandan xinli can be conceptualised as a case of "infrastructural entrepreneurship," a business whose missionthough this might not be entirely clear even to its founder-is to build the necessary infrastructure - the grounds on which various actors, objects, and technologies can operate and move around - not only for its own operations and profit but also for the development of the field of psychotherapy. I begin the discussion with a brief review of the psycho-boom, paying specific attention to the shortcomings at its infrastructural level that became apparent when the Mental Health Law was about to be administered. I then delineate Li's trajectory from an Internet personality to an e-commerce entrepreneur, highlighting the emerging infrastructure that made her pursuits possible: social media and the startup eco-system. Subsequently, I turn to the platform itself, examining the features that are designed to tackle the field's shortcomings. I use ethnographic methods to demonstrate how it has achieved tentative success as infrastructure, lending support to a part of a field that is, on the one hand, a new mental health services sector, and on the other, a burgeoning occupation awaiting transformation into a profession. Finally, I discuss the risks and potential vulnerabilities of the platform and the implications of this case for the development of mental health in China.

Informed by my long-term research on the development of psychotherapy in China, ${ }^{(9)}$ this article makes use of information taken from interviews, participant observation, and media accounts related to jiandan xinli. I first met and interviewed Li Zhen in the summer of 2014, within a few weeks of the launch of the platform, as part of my efforts to "study up" (Nader 1972) and become cognizant with the latest trend in e-commerce entrepreneurship. I conducted four additional interviews with her in August and December 2016 and June and August 2017. (10) These interviews were guided by the principle of "person-centred interviewing" (Levy and Holland 1998) and directed toward gaining an experience-near understanding of her activities. In the past three years, I have attended several lectures and workshops given by Li herself or held by the platform; these events have given me further opportunities to observe her project in action and to talk with her briefly. I have also discussed all aspects of the platform with most of my informants, including more than 20 therapists who are associated with it. I have followed $\mathrm{Li}$ and the platform closely in the online world; both have an active presence on social media and are regularly covered by digital media.

\section{The psycho-boom and its infrastructural shortcomings}

The psycho-boom, which began to emerge in major Chinese cities in the early 2000s, includes several interrelated phenomena: a craze for psychotherapy "training," (11) a proliferation of therapy personnel and services, and the infiltration of ideas and values associated with psychotherapy and psychology into popular culture. The trend, which departs drastically from the Maoist period, in which psychotherapy was denounced as a bourgeois practice and prohibited, (12) has received considerable attention from scholars studying contemporary China. Seeing the parallels between the Chinese development and the historical "triumph of the therapeutic" (Rieff 1966) in the United States, this new and still evolving scholarship focuses on various aspects of the flourishing scene, including the political implications and meanings of therapeutic expertise (Yang 2015; Zhang 2017a; Hizi 2017), the cultural adaptation of imported technologies (Zhang 2014; see also Hizi 2016), the cultivation of new subjectivity (Zhang 2017b), and the interplay between popularisation and professionalization (Huang 2014, 2017). However, the dominant narrative within the psycho-boom posits an uncomplicated correlation; it is assumed that the demand for therapy will increase quickly along with rapid economic development, which has brought about an alleged mental health crisis ${ }^{(13)}$ and enhanced public concern for mental well-being. This optimistic assessment prevailed for almost a decade until the mental health legislation cast doubts on it.

What has happened on the ground is far less straightforward. The psychoboom took shape on top of a set of apparatuses—government policies, professional actions, and commercial investments-that constitute its infrastructure. In both scholarly and popular accounts, the certification program for "psychological counsellors" (xinli zixun shi 心理咨询师), which was

7. Interview by the author, Beijing, 20 December 2016.

8. For some of the most representative studies on infrastructure in its traditional sense, see Harvey and Knox (2015), Mains (2012), and Anand (2011). For a now classic study on immaterial infrastructure, see Bowker and Star (1999). For a recent discussion on "migrant infrastructure," see Xiang and Lindquist (2014). Medical anthropology and global health have long endorsed the insight that infrastructure is more important than culture, but the term only became a focus of theorisation recently; for example, see Street (2014) and Seo (2017). For efforts to develop it as a conceptual tool, see Larkin (2013) and Howe et al. (2016).

9. My research began in 2008 and is ongoing at the present moment. It addresses these questions: How does the development of psychotherapy in China assume the form of a boom, a "fever" (re), or a popular movement? What kind of subjectivity is being produced in the psycho-boom? What are the prospects for the new mental health profession that is emerging from it? I conducted continuous fieldwork between September 2009 and July 2011, primarily based in Beijing but with Shanghai as a secondary site that I visited occasionally. After a period of absence during which I maintained close contact with my key informants via the Internet, I visited Beijing again in the summer of 2014, and have visited regularly ever since, with the duration of each visit lasting from one week to one month.

10. All of the interviews were conducted in person during my visits to Beijing, except for that in June 2017, which was conducted online.

11. In the psycho-boom, the term "training" (peixun) refers to all kinds of events at which knowledge and techniques derived from psychotherapy are taught. Many of them are not linked to a professional purpose.

12. For a historical review of the development of psychotherapy in modern China, see Huang (2015).

13. The Chinese government used to be reluctant to acknowledge the significance of mental health issues. This has drastically changed since a large-scale public mental health reform was initiated in the early 2000 s. For the appalling figures- $17.5 \%$ overall prevalence rate, which can be translated into 173 million people suffering from mental illness - that are routinely cited by the state, see Phillips et al. (2009). 
launched by the Ministry of Labour and Social Security (14) in 2002, is deemed an essential part of this underlying formation. The program adopted a "rapid assembly line" (Zhang 2014, p. 288) model-it took merely a few months of part-time learning — and could accommodate people with various backgrounds and motivations. Its impacts on the psycho-boom were profound. As I argue in my historical review (Huang 2014), the program not only created an alternative pathway of training outside higher education and medicine but also transformed training into a commodity, one that was packaged as beneficial to either career development or personal growth. As studying psychotherapy became popular among members of the middle class, the program laid the foundations for an industry that featured an expanding array of ultra-short programs in addition to the prep course for certification. The industry also supported a group of celebrity teachers, mostly senior psychiatrists or psychologists, who toured the country giving lectures and holding workshops.

The craze for training would become the basis for a new mental health services sector, which operated in an institutional context that differed from that of the existing system in crucial ways. Its members, not qualified to enter the medical system, had to work at private counselling centres or practice individually; both settings fell outside the jurisdiction of the health authorities and were situated in a legal grey zone. In contrast, the existing system was virtually identical to public psychiatry. It had grown substantially under the mental health reform ${ }^{(15)}$ inaugurated after the 2003 SARS epidemic, but its complement of some 20,000 psychiatrists nationwide could well have been outnumbered by the new sector. The accumulated number of people who passed the Ministry of Labour certification had grown swiftly-300,000 in 2011 and 600,000 in 2014-though the percentage of graduates who went into practice remained relatively low (probably $10-15 \%)$.

The psycho-boom escalated in the aftermath of the 2008 Wenchuan earthquake thanks to the state's promotion of post-disaster mental health. In 2011, it faced another turning point when the draft Mental Health Law was announced in June. The draft adopted a medical definition of "psychotherapy" (xinli zhiliao 心理治疗), differentiating it from "psychological counselling" (xinli zixun 心理咨询), which had been considered its equivalent since the rehabilitation of psychology in the early reform period. (16) This "medicalisation" of psychotherapy was perceived as a threat by those who entered the field through the Ministry of Labour certification. The final phase of the legislation - from draft-stage to the promulgation of the law in May 2013 - was thus suffused with uncertainty. Members of the psycho-boom engaged in collective meditation on the ramifications of the law and the prospects for the field. Two problems were widely acknowledged and discussed; both were pertinent to infrastructure, or more specifically, the lack thereof.

The first was the widespread perception that the field was dominated by anarchy and chaos due to the rudimentary status of professionalization. I explored this subject in my ethnographic examination (Huang 2017) of the debate following the release of the draft Mental Health Law, in which two keywords-jianghu (江湖, literally "rivers and lakes") and professionloomed large. During this period, jianghu, a term that referred to an "untamed realm," became a popular metaphor for the field. The typical pathway to becoming a practitioner-first passing the Ministry of Labour certification and then attending some other short-term programs provided by the training industry-was now considered seriously inadequate. Some therapists went so far as to postulate that training in China, instead of serving a professional purpose, was merely a means of popularisation, since it allowed people to gain psychological knowledge in a flexible and direct manner. Concurrently, the elite psychiatrists and psychologists who made up the Registry System under the Chinese Psychological Society came forward to promote and implement the idea of professionalization. Established in 2007, the system showed a clear intent to emulate the model of Western-style professional associations, distinguishing itself from more traditional organisations (17) by constructing some of the infrastructural components of a profession-rigorous criteria and a code of ethics. ${ }^{(18)}$ In 2011, consisting of some 400 members, it was still rather small, but its visibility and influence would gradually increase in the ensuing years.

The second was the disappointing outlook for private practice. Those who ventured in that direction usually found that the path was not as promising as portrayed by the training industry. Back then, even in Beijing, which had the most full-blown psychotherapy scene in China, most of the therapists I knew had very few clients. ${ }^{(19)}$ As could be expected, referral among colleagues-a common channel for gaining new clients in the West-seldom occurred. Referral from medical doctors was even rarer, though psychiatric clinics in hospitals had plenty of patients and some of them might have been suitable for therapy. The two systems-public psychiatry and the private practice sector-were segregated from each other and had little interaction. Psychiatrists also tended to be biologically oriented; many of them were hostile to or suspicious of talk therapy and its practitioners. Under such unfavourable circumstances, therapists in private practice often adopted strategies such as setting up a free hotline, writing personal blogs, and purchasing keyword advertising services from Baidu, China's dominant search engine. ${ }^{(20)}$ As none of these methods was particularly productive, increasing numbers of therapists found themselves disillusioned. The consensus seemed to be that it was much easier to make profits from teaching in the training industry than from practicing psychotherapy.

\section{Jian Lili: From Internet personality to entrepreneur}

During the final phase of the mental health legislation and in its immediate aftermath, Li Zhen went through successive career transformations that turned her into an e-commerce entrepreneur. Born in 1986, she had amassed some unusual experiences that few of her peers could imagine: a Henan native, she was treated as a genius by her family and began formal education at

14. In 2008 , the Ministry of Labour and Social Security merged with the Ministry of Personnel to form the new Ministry of Human Resources and Social Security, which has overseen the program ever since. Following the customary usage of my informants, I use the abbreviated title "Ministry of Labour" to denote both the old and the new Ministries in the following sections.

15. For the mental health reform, see Liu et al. (2011). For a brief introduction to its core component, the so-called "686 Program," see Ma (2012).

16. For a detailed explanation of the distinction, including its historical precedents in the West and its perception in China, see Huang (2017, pp. 6-8).

17. Until then, the most powerful professional association in the field had been the Committee of Psychotherapy and Psychological Counselling under the China Association for Mental Health. The committee was founded in the early 1990s and was involved in the creation of the Ministry of Labour certification.

18. For the early history of the Registry System and the development of its code of ethics, see Zhong et al. (2008) and Qian et al. (2009).

19. This is a widely acknowledged fact in the field. For a survey that shows the grim situation, see Zhang et al. (2010). Despite the lack of clients, most of the therapists had the financial resources to maintain their practices for a while.

20. This latter strategy is also common in China's private healthcare sector, especially among the medical conglomerates collectively known as the "Putian Clan" (putian xi). For a discussion of this phenomenon and a recent scandal, see Li (2016). 
the age of four. She entered college at 15, and after that went abroad to study Cognitive Neuropsychology at University College London. ${ }^{(21)}$ She returned to China in 2008 with a Master's degree and soon began working as a counsellor/lecturer ${ }^{(22)}$ at the Central University of Finance and Economics in Beijing. In 2012, she became an Internet personality while keeping her daytime job and moonlighting in private practice. ${ }^{(23)}$ In 2014, she left the university and stepped onto the entrepreneurial path to launch Jiandan xinli. These metamorphoses were embedded in two kinds of infrastructure that were available around the time of their occurrence: social media and the eco-system for startup entrepreneurship.

Li initiated her e-journey from the social media platform Douban (豆瓣) Established as early as 2005, Douban was considered a peculiarity in China's social media landscape. Its popularity had never been anywhere close to that of Weibo or WeChat; however, over the years it had become a social space that was particularly appealing to young people interested in literature and the arts一-so-called "cultured youth" (wenyi qingnian 文艺青年). The main reason for this evolution, as Zhang (2016) indicates, lay in the platform's settings, which enabled its users to make connections based on shared interests in books, music, drama, and movies. The platform's users and its built-in features-personal blogging and online group participation-would support the rise of $\mathrm{Li}$ as an author who specialised in writing about psychological experiences and psychotherapy. Her audience, mainly her contemporaries, were more psychologically minded and sophisticated than their senior cohorts-traits that derived from the cultural dissemination of psychology during the previous decade of the psycho-boom.

At the beginning of 2012, Li was invited by a friend to join the Douban group he managed, an online "club" that featured the sharing and discussing of relationship problems. The friend assigned her a duty not dissimilar to her daytime job-offering advice to other members. Immediately she noticed that people kept asking the same questions, and this prompted her to write more extended notes on her Douban page to address them more substantially. In late February, she made her debut with an article entitled "To Become Yourself" (chengwei ni ziji 成为你自己). In May 2012, she changed her alias from "Jane Whisperer" (Jane is her English name) to Jian Lili, (24) the name by which she was best known thereafter. By then she had made her name as a well-liked writer on Douban. Before she moved on to pursue a business career in early 2014, she had published about 50 articles, which were later compiled into a book. ${ }^{(25)}$ She had a substantial following of more than 20,000 people ${ }^{(26)}$ with whom she interacted actively. It was one of the largest "fandoms" on Douban.

Writing for a popular audience, along with other media experiments she conducted concurrently, (27) made Li a renowned "populariser" —an individual who was proficient at popularisation or transforming professional knowledge into information accessible to the general public. ${ }^{(28)}$ The inner self-with its intricacies and shadows - and therapy — cast as a relational process fraught with uncertainty but conducive to self-exploration-were the two recurring themes in her works. The first theme tackled experiences associated with the psychological subjectivity that had increasingly come to define middleclass culture in China. ${ }^{(29)}$ Li was particularly interested in psychoanalysis, and she was capable of offering descriptions and insights that far exceeded the depth of those offered in the popular self-help or "chicken soup" (jitang 鸡 汤) literature. (30) The second theme involved the psychological modality that, despite a decade of psycho-boom, remained mysterious and mystified in the public consciousness. Although authors associated with the psycho-boom incessantly talked about therapy on web-forums, blogs, and Weibo, most of them were less sophisticated than Li, yet exuded a clearly inflated sense of authority. Conversely, Li took pains to explain the nitty-gritty of therapy in a warm and genuinely sincere tone. ${ }^{(31)}$

With therapy looming large in Li's writings, readers began sending messages to her in droves to inquire about it. Some of them asked general questions about the essential qualities of a competent therapist, while others posed more direct requests, asking her to recommend one. She did some research and was surprised that no one in China had written an accurate and reliable guidebook for potential clients of therapy. The existing materials were indistinguishable from advertisements. Composed by therapists with the aim of promoting their own businesses, these texts exaggerated the effects of therapy and overstated the capabilities or qualifications of the authors-a phenomenon symptomatic of the unruly state of a field that was, as noted above, compared to the untamed realm of jianghu. In response, Li wrote "A Guide to seeking psychological help" (xinli qiuzhu zhinan 心理求 助指南), which was published on Douban in August 2012 and soon became one of her most widely circulated articles. In this checklist-style piece, she presented ten things that a client needed to know about therapy and the therapist he or she was planning to consult, including the distinction between a practitioner and a researcher, the settings for therapy, the issue of safety, and the client's right to choose the right therapist and to negotiate the specifics of the treatment. (32) These tips might seem like basic knowledge, but as I understand it, no one in China had written on the subject before Li made the pioneering move.

21. Li talked about her life story, including childhood experiences, quite openly in many media interviews conducted in the early days of her startup career. For a particularly detailed interview conducted before she began to write on Douban, see "Wo shi sanmingzhi No. 36 Li Zhen" (I'm a sandwich no.36 Li Zhen), China 30s, 3 January 2012, http://story.china30s.com/2592.html (accessed on 20 May 2017).

22. In China, full-time university counsellors typically hold the title of lecturer. Besides counselling, their duties include teaching and administration.

23. Many therapists keep their full-time jobs-including mental health-related jobs in hospitals or universities - while managing their practice as a sideline business.

24. At that time, Li chose to use the pseudonym in order to prevent her superiors from knowing that she was engaging in outside activities.

25. See Li (2015).

26. The number might seem small when compared to the celebrities on Weibo or WeChat, many of whom boast hundreds of thousands of followers. Back in 2012 and 2013, the most popular social media platform in China was Weibo. This Chinese version of microblogging also imposed a 140-character limit. In comparison, Douban was much more suitable for writing and reading texts of substantial length.

27. Between 2012 and early 2014 , Li had explored a number of media opportunities, including TEDlike presentations, podcasts, and MOOC. She did well in all these venues; for example, the podcast program she co-produced with two friends, including her boyfriend He Feng, "Knowledge party" (zhishi paidui), once made the top-ten list of Chinese-speaking podcasts on iTunes.

28. In the history of psychotherapy, some of the most famous "popularisers" are themselves practitioners; for example, Benjamin Spock, Karl Menninger, Donald Winnicott, and lately the controversial Dr. Phil. All have used traditional mass media—print press, radio, and TV—as the medium of transmission, while Li Zhen relied on the Internet and social media. For discussions on the popularisation of psychotherapy and psychology, see Burnham (1987) and Illouz (2008).

29. There is a turn toward the individual, the inner, and the psychological in the recent ethnographies on China. Notable examples include Hansen and Rune Svarverud (2010), Kleinman et al. (2011), and Kipnis (2012).

30. For the rise of this genre in China, see Hendricks (2016). The term "chicken soup," which derives from the Chicken Soup for the Soul book series, has become a buzzword in China. It carries sarcastic overtones, suggesting that this genre is superficial and naive.

31. For example, in her debut article she wrote, "A simple explanation would be that psychological counselling does not help people to solve problems. True, it doesn't. A counsellor cannot tell you whether you should quit your job or not, whether you should get back together with your girlfriend, or how to overcome nerves on stage. The only thing he or she should do is to help you to understand and accept yourself and to explore the treasure in your heart, so that you will have the courage and power to live your life in your own way." See Li Zhen (Jian Lili), "Chengwei ni ziji" (To become yourself), Jian Lili (Douban page), 22 February 2012, https://www.douban.com/ note/201935064/ (accessed on 20 May 2017).

32. Li Zhen (Jian Lili), "Xinli qiuzhu zhinan" (A guide to seeking psychological help), Jian Lili (Douban page), 10 August 2012, https://www.douban.com/note/230270172/ (accessed on 20 May 2017). 
These suggestions, however, could not resolve the concrete problem of locating a therapist, and Li's determination to find a solution would lead to the creation of Jiandan xinli. Throughout 2013, she received 20 to 30 emails daily asking for a "referral" to a colleague whose professional abilities were approved by her-she was trusted as an arbiter of professional competence. These queries became a burden that she could barely handle. Yet from them she also gained a unique niche — contact with thousands of people who were contemplating seeking therapy - that enabled her to evaluate the problems perturbing the field: the disappointing career outlook and the lack of professionalization. Li discovered that these readers were highly motivated to pursue therapy, open to an extended course of treatment, and capable of affording such costly services. On the other hand, they were deeply concerned about the quality of what was being offered; alarmed by the chaos of the field, they were afraid of falling victim to swindlers or incompetent therapists. Li concluded that there was indeed a strong and growing need for therapy and that to tap into it would require a system that could make the connections and assure quality control. As a result of this assessment, she began to entertain the idea of a nationwide Internet-based referral system that would link clients and carefully selected therapists. She later described this infrastructural solution to me as a gigantic "hospital in the air" (kongzhong yiyuan 空中医院) it would be a virtual institution without walls and floors but staffed with therapists who, like medical doctors, were certified by a trustworthy authority. ${ }^{(33)}$

Li decided to bring this concept into reality by starting a business, a transformation that accelerated in the first months of 2014. (34) In January, she went to Silicon Valley to attend a startup training program at Draper University, founded by the renowned venture capitalist Tim Draper. She pitched her idea and won an angel investment from Tim upon graduation. After returning home from the United States, she attracted additional investments from two domestic venture capital firms, including the Zhen Fund (zhenge jijin 真格基金) founded by the eminent entrepreneur Xu Xiaoping. She quit her job and launched the company in April. He Feng (何峰), (35) then her boyfriend-they married recently — and the co-founder and COO of Jiandan xinli, played a critical role in this transition. As the co-founder of the first crowdfunding website in China, Demohour (dianming shijian 点名时间), he was a veteran of Beijing's startup circles and had introduced Li to the startup community, offering useful advice and unreserved support along the journey.

Jiandan xinli belonged to a startup trend that was turning into a frenzy, one that relied heavily on the burgeoning startup ecosystem - the infrastructure that derived from the Chinese state's latest efforts to enhance industrial upgrading and to create a service-oriented, innovation-based economy. ${ }^{(36)}$ At the Summer Davos held in Tianjin in September 2014, Premier Li Keqiang made the first public call for "mass entrepreneurship and innovation" (dazhong chuangye wanzhong chuangxin 大众创业、万众创新). The motto became a pillar of the national economic policy in 2015. ${ }^{(37)} \mathrm{Co}$ working spaces, incubators, and innovation parks, which received generous government subsidies, were mushrooming in major cities. These agencies, together with the young industry of venture capital, formed a comprehensive eco-system for startup businesses. What ensued was a wave of entrepreneurship distinguished by its appeal to youth and its emphasis on technological innovation, most of which involved the Internet, a trend that dovetailed with the concurrent "Internet plus" (hulianwang jia 互联网 + ) policy. ${ }^{(38)}$ Beijing was at the heart of this evolution. Even before that, a startup scene had begun to thrive in Zhongguancun (中关村), an area that, with its proximity to China's most elite universities, was morphing into its version of Silicon Valley. ${ }^{(39)}$ The first office of Jiandan xinli was also located in this region.

\section{Jiandan xinli: An e-commerce platform as digital infrastructure}

Jiandan xinli went online in June 2014. In the beginning, it only existed in web format -its mobile app version would appear in January 2015-but it already contained most of the crucial features that would be adjusted and improved as the company rose to prominence. The form it adopted was an e-commerce platform, which had become an essential kind of infrastructure for the so-called "platform economy" (Kenney and Zysman 2016). The specific design of the platform was facilitated and conditioned by the $\mathrm{O} 2 \mathrm{O}$ (online-to-offline) model that had begun to sweep the field of e-commerce at that time. However, Li also found it necessary to modify the model based on her understanding of psychotherapy as a professional service rather than merely a trade. The platform had three main elements: an interface for selecting a therapist and making an appointment, which supported e-payment; a channel to transmit psychology and attract potential clients, which mostly depended on social media; and a system of recruitment that involved meticulous standards of training and qualification.

2014-the year Jiandan xinli was established—witnessed a new trend in China's already vibrant e-commerce. Previously, it had been dominated by

33. Interview by the author, Beijing, 10 July 2014.

34. Li has talked about her startup story in many media interviews. For two particularly detailed accounts, see Nuan Huhu, "Zoxia ziji de xuanai hou, rang gengdou ren zoxia xinling de xuanai" (Helping others after she steps back from the cliff), China 30s, http://www.china30s.com/portfolio/a三明治故事-story/简里里 : -走下自己的悬崖后, 让更多人走下心灵的 (accessed 20 May 2017); An Xi, "Jiandan xinli Jian Lili: cong jiujie dao chuangye qishi shige jinhua de shi" (Jiandan xinli Jian Lili: from a dilemma to start up one's business. It's a progress), NetEase Tech 163, 9 March 2015, http://tech.163.com/15/0309/07/AK8HJPE400094P5B.html (accessed 20 May 2017).

35. He is a Beijing native who went abroad at a young age. Attending high school in Singapore, he studied mathematics and computer science at Swarthmore College in the U.S. and eventually obtained an MBA from Stanford University. He and Li are the protagonists of an urban legend. One day in $2011 \mathrm{He}$ ran into a charming girl on the subway. They briefly chatted but did not leave any contact information. He wrote a note on Weibo, which had just emerged as a popular social media platform back then, and the note was widely circulated, which helped him to reach the girl. While she already had a boyfriend, this event, which was one of the stories featured in the 2012 documentary film Weibo, brought him into contact with Li.

36. This startup frenzy has received enormous attention from domestic and international media. For a few notable examples, see Lu Rachel, "China, Start-up Nation," Tea Leaf Nation/Foreign Policy, 22 April 2015, http://foreignpolicy.com/2015/04/22/china-startup-nation-from-factory-to-techincubator/ (accessed on 30 September 2016); Clive Thompson, "How a Nation of Tech Copycats Transformed into a Hub for Innovation," WIRED, 29 December 2015, https://www. wired.com/2015/12/tech-innovation-in-china/ (accessed 20 May 2017); Michael Schuman, "Venture Communism: How China Is Building a Start-up Boom," The New York Times, 3 September 2016, https://www.nytimes.com/2016/09/04/business/international/venture-communism-howchina-is-building-a-start-up-boom.html?_r=0 (accessed 20 May 2017).

37. The Chinese state has issued a series of policy directives related to this campaign. For one of the most important documents, see State Council, "Guanyu dali tuijin dazhong Chuangye wanzhong chuangxin ruogan zhengce cuoshi de yijian" (Opinions on certain policies about the promotion of mass entrepreneurship and innovation), 16 June 2015, http://www.gov.cn/zhengce/content/ 2015-06/16/content_9855.htm (accessed 20 May 2017).

38. The Chinese state has also issued policy directives related to this campaign. For one of the most important documents, see State Council, "Guanyu jiji tuijin hulianwang jia xingdong de zhidao yijian" (Guidelines on promoting the "Internet +" project), 2015, http://www.gov.cn/zhengce/ content/2015-07/04/content_10002.htm (accessed May 20 2017). See also Ma (2015).

39. For example, Steve Blank, a renowned entrepreneur who authored The Four Steps to Epiphany and The Startup Owner's Manual, described Zhongguancun as China's Silicon Valley on his blog (www.steveblank.com) after his 2013 Beijing trip. See also Paul Mozur, "Inside China's Version of Silicon Valley: Entrepreneurs, Investors Rub Elbow in Beijing's Zhongguancun District," The Wall Street Journal, 4 December 2013. https://www.wsj.com/articles/inside-china8217s-version-ofsilicon-valley-1386118411 (accessed 20 May 2017). The startups in Beijing tend to focus on software. Shenzhen is another Chinese city that is often compared to Silicon Valley, but the companies there mostly focus on hardware. 
the horizontal or marketplace model epitomised by the Internet giant Alibaba, ${ }^{(40)}$ whose IPO on the New York Stock Exchange in June 2014 was highly encouraging news for the startup scene. Its two principal platforms, Taobao (淘宝) and Tmall (天猫), which adopted the C2C (customer to customer) and B2B (business to business) models, respectively, were websites on which one could find and purchase almost everything. By this stage, $\mathrm{O} 2 \mathrm{O}$, an overly broad and fluid concept that involved enticing people online and directing them to consume products or services offline, had become the Holy Grail. Introduced into China around 2010, the concept first informed a proliferation of Groupon-like websites, which soon slumped into what was ridiculed as "the battle of a thousand group-buying websites" (qiantuan dazhan 千团大战). However, when the same term became a buzzword again in the startup frenzy, it was associated with the vertical model of e-commerce that focused on specific types of services. Numerous companies that emerged in 2014 and 2015 took it as their guiding principle; they built a platform — typically a mobile app as mobile payment and commerce had become commonplace (Ma 2017) — to connect consumers and particular kinds of services providers. The $\mathrm{O} 2 \mathrm{O}$ trend reached virtually every business field, with the most successful examples including dining and takeout delivery (for example, Meituan 美团 and Dazhong Dianping 大众点评, which merged in 2015) and taxi-hiring (such as Didi Chuxing 滴滴出行, which bought its rival Uber China in 2016). (41)

The kernel of Jiandan xinli, and of $\mathrm{O} 2 \mathrm{O}$ platforms in general, was to connect human and material resources so that business transactions could occur more seamlessly. Taking the role of an intermediary or simply a link, Jiandan xinli served both sides of the therapeutic relationship —clients and practitioners. For the former, it offered a reasonably large inventory of qualified therapists to search and choose from. An appointment could be made online with ease-either on the website or via the app — with the fee being paid in advance through popular e-payment options such as Alipay, WeChat Pay, or credit card. For practitioners, it provided a constant supply of clients who tended to be psychologically minded. Therapists had to pay a "platform usage fee" (tentatively set at $5-15 \%$ of what they earned through the platform). ${ }^{(42)}$ It was, however, the platform that received the payments from clients in the first place, and it would transfer the earnings, with the usage fees deducted, to the therapists monthly. This strategy, which was a regular practice across the $\mathrm{O} 2 \mathrm{O}$ platforms, created an advantage in terms of cash flow.

Jiandan xinli, while sharing many commonalities with other $\mathrm{O} 2 \mathrm{O}$ platforms, has demonstrated critical distinctions. In our second interview, in the summer of 2016 - by then the once feverish $\mathrm{O} 2 \mathrm{O}$ startup trend had begun to diminish-Li Zhen reminisced about the early days of the company. Describing it as an anomaly in the $\mathrm{O} 2 \mathrm{O}$ scene, she rebuffed the idea that the same model could be applied to all business fields. "Many people have the fantasy of building a Didi or Uber for psychotherapy services," she said. "That may be an attractive idea for them. But for me, it is pure nonsense." (43) What she emphasised instead were the differences between psychotherapy and more mundane services - psychotherapy required well-trained professionals and entailed a relationship that was at once intimate and instrumental. With this ideal in mind, she realised that some of the common practices in the $\mathrm{O} 2 \mathrm{O}$ industry had to be modified or relinquished. Like other digital platforms, Jiandan xinli has undergone numerous changes and upgrades. ${ }^{(44)}$ Now the platform offers a dazzling array of services targeting different mental health and professional needs. These are the outcome of collaborative work between Li and her rapidly expanding crew. Initially a three-person startup, the company now has more than 40 employees filling a diversity of positions, including software developer, graphic designer, content producer, human resources specialist, customer service representative, and so on. However, over the past three years the core functions or components of the platform have remained relatively stable.

The first is an interface for searching and making an appointment. The platform features a menu in which one can use a series of parameters, including means of treatment (online or in person), location, sex, price range, problem of concern, age group and identity, and therapeutic orientation, to conduct a search. It is equipped with a matching tool that can recommend a few therapists based on a questionnaire filled out by the candidate. On the platform, each therapist has a personal page; they are not only required to provide a comprehensive resume-including biography, education and training credentials, and current status regarding supervision and personal treatment-but are also encouraged to post articles and short videos to introduce themselves more comprehensively. To make an appointment, a potential client must choose from the available time slots shown on the therapist's page and submit an application. If the therapist accepts it, he or she will offer further information so that the treatment can occur in person or online. Li pointed out to me that the process was intentionally designed to be complicated-this was in stark opposition to the impulse-driven, "one-click" purchase that most O2O platforms would encourage-to respect the magnitude of the decision to begin therapy. ${ }^{(45)}$

The second core function is to operate as a channel to disseminate popular knowledge. Jiandan xinli derived from Li's previous career as an author on Douban, from which it gained enough clients to support its initial operations. Since then, Li has amplified media efforts, adapting them to the changing social media landscape in China to maintain the lead in popularisation, which had proved to be the most effective way to reach potential clients. She kept the Douban site but moved the primary base to WeChat, ${ }^{(46)}$ which had replaced Weibo as the most popular social media platform in China by 2014, while establishing a lively presence on Zhihu (知乎), a Q \& A website launched in 2011. Li, who used to be the sole author, later assumed the role of supervisor, and most of the content on the platform was created by the therapists affiliated with it and her employees. In 2016when "content entrepreneurship" (neirong chuangye 内容创业) became a guiding concept for the startup scene-she established a new division called "content lab" (neirong shiyanshi 内容实验室) to produce and manage the

40. Globally, the most well-known example of the marketplace model is the American e-commerce giant Amazon. See Stone (2013).

41. For a survey of this $\mathrm{O} 2 \mathrm{O}$ trend, see Carton Mansfield Capital, "China O2O Industry Report 2014," 13 January 2015, http://www.carltonmansfield.com/wp-content/uploads/2015/02/CML-ChinaO2O-Industry-Report-2014.pdf (accessed 20 May 2017); Kevin Wei Wang, Alan Lau, and Fang Gong, "How Savvy, Social Shoppers Are Transforming Chinese E-Commerce," McKinsey, April 2016, http://www.mckinsey.com/industries/retail/our-insights/how-savvy-social-shoppers-are-transforming-chinese-e-commerce (accessed 20 May 2017).

42. The rate varies based on the number of sessions conducted. It is $15 \%$ for the first 15 sessions, $10 \%$ for the next 15 sessions, and lowered to $5 \%$ after that. These rates are significantly lower than the "rent" that part-time therapists pay to the owners of counselling centres (often as high as 40 or $50 \%$ of income)

43. Interview by the author, Beijing, 18 August 2016

44. For a candid discussion on how to build a digital platform of another sort-the website of the journal Cultural Anthropology—see Kenner (2014), Elfenbein (2014), and Fortun and Fortun (2015)

45. Interview by the author, Beijing, 10 July 2014.

46. In the beginning, WeChat, with its extremely popular "public account" (gongzhong hao) feature, merely served as an organ of popularisation for Jiandan xinli. However, the WeChat site has incorporated many new functions-including the platform's core function of making an appointment-as WeChat becomes more mature and dominant as a digital infrastructure. 
textual and occasionally multimedia content across various platforms. ${ }^{(47)}$ Now the platform is churning out articles at a speed unimaginable in Li's Douban era-almost on a daily basis.

The two components described above are meant to address the underlying problems that led to the perception of dwindling prospects in the new mental health services sector of private practice. Jiandan xinli as a digital platform can bridge the two populations that were previously disconnected. In terms of client base, popularisation endeavours to ensure a substantial and growing supply of clients. The remaining issue pertains to practitioners, and is addressed by the third core component of the platform. This is the rudimentary status of professionalization, of which Li, as a member and a keen observer of the psycho-boom, is well aware. In our second interview, she mentioned a few online psychotherapy platforms in the United States and explained the challenge of setting up a similar business in China:

In many Western countries, psychotherapy is a relatively mature profession. There are state-sanctioned licensing systems for psychiatrists, psychologists, and social workers. A variety of professional associations and training institutions further work hand-in-hand to ensure the competence and ethical conduct of therapists. In China, the field is so new and chaotic. We as a platform therefore need to take up the task of quality control. (48)

By "quality control," Li was referring to a system of objective rules. She defied the common $\mathrm{O} 2 \mathrm{O}$ practice of first expanding the army of service providers, and then leaving the issue of quality to consumer ratings and reviews. In the beginning, she recruited therapists mainly through her personal networks; she had been involved in a few acclaimed training programs, through which she had come to know a small group of proficient colleagues. The platform was also open to applications, with candidate assessment being based on the "standards of entry" (ruzhu biaozhun 入 驻标准) (49) set down by Li. The requirements included completion of a longer-term training program (at least two years), a minimum of 1,000 hours of individual psychotherapy practice, a minimum of 60 hours of supervision, a minimum of 100 hours of personal treatment, ${ }^{(50)}$ and endorsement by two therapists affiliated with the platform. In 2016, the platform established a more detailed procedure of evaluation, whose design was informed by the Benchmarks Model of the American Psychological Association. ${ }^{(51)}$ Now the candidate is obliged to submit a case report and undergo an oral interview, conducted either in person or online by the senior therapists collaborating with the platform. The interview is intended to be a balanced and comprehensive assessment that ranges from technical skills to ethical competence.

\section{Infrastructural success and a surrogate professional association}

As noted above, Jiandan xinli was designed by Li to address the infrastructural problems that had become manifest around the time of the mental health legislation: the disconnection between clients and therapists in the new mental health services sector and the prevalence of incompetent therapists in the unregulated profession. How well does the platform solve these problems for its users? Can it serve as a stable supporting structure for the field, or at least a part of it? To answer these questions, I draw on my fieldwork observations and interviews with the therapists affiliated with the platform-
I had known them during my 2009-2011 fieldwork, which occurred well before they joined it. ${ }^{(52)}$ The gist of my findings is that Jiandan xinli does achieve an "infrastructure success," as it can efficaciously provide a bridge between clients and therapists who are selected based on its standards. These standards have not only become an important benchmark for excellence in the field but have also turned the platform into a surrogate professional association, the kind of organisation that typically assumes the leading role in a project of professionalization or the construction of a professional infrastructure, including certification, standardised training, code of ethics, and so on.

Jiandan xinli gained an impressive reputation as a psychology-related digital startup ${ }^{(53)}$ quite soon after its launch. In July 2015, I visited Beijing to attend the fourth national conference of the Registry System, an event that featured an official theme of professionalization and an informal yet even more popular theme of the "Internet age" (hulianwang shidai 互联网时代), which had become the talk of the town due to the startup frenzy. Li was in the spotlight during the conference. When she appeared at a forum on psychotherapy in the digital age, she received far more applause than other renowned therapists. Her company's booth drew the largest crowd at the exhibition; conference participants also relished talking about her and the platform. By that stage, the platform had expanded to about 170 therapists, who resided in 45 cities in China and abroad, and claimed a steady growth in the numbers of clients and sessions that occurred through it. Moreover, it had raised more than one million U.S. Dollars of venture capital (54)_this was exhilarating news to people who were involved with the psycho-boom because it reaffirmed the potential of psychotherapy. Several months later, it concluded its Series A funding, gaining an additional several million U.S. Dollars, ${ }^{(55)}$ while the startup scene in Beijing was experiencing an unexpected downturn in the socalled "winter for venture capital" (ziben handong 资本寒冬). ${ }^{(56)}$

The early success of the platform lies in its ability to solve practical problems. In terms of its efficiency in providing clients, all the therapists I know

47. Li continued to explore various media opportunities both within and outside social media after the founding of Jiandan xinli. These include: live streaming, podcasting, online courses, and onsite speeches or workshops.

48. Interview by the author, Beijing, 18 August 2016

49. For the current version of the standards, see http://www.jiandanxinli.com/pages/34 (accessed on 10 October 2017).

50. The incorporation of the requirement for personal treatment in the standards reflected both Li's personal penchant for psychoanalysis and the overall psychoanalytic dominance in China's psycho-boom. In the latest version of the standards, this requirement only applies to therapists who claim to offer psychoanalysis ( 300 hours of personal analysis required) or psychodynamic psychotherapy (100 hours of personal treatment required).

51. For a recently published explanation of how Jiandan xinli conducts its evaluation, see https://www.jiandanxinli.com/materials/537 (accessed on 10 October 2017).

52. The users of Jiandan xinli include both therapists and clients. However, the data presented below is constrained by the scope of my long-term research—I have long focused merely on therapists and trainees.

53. Thanks to the psycho-boom, many entrepreneurial minds saw the potential of turning psychotherapy or broadly defined psychological assistance into a business. More than 20 psychology-related startups emerged during 2014-2015. For an incomplete compilation of these companies, see Shen Xiaoxue, "Zihai zhuan gangxu: naxie app shuaixian jishen hulianwangjia xinli zixun saidao?" (From speculation to strong demand: the apps that lead the Internet + trend in psychotherapy), Lieyunwang, 21 October 2015, http://www.lieyunwang.com/archives/123447 (accessed on 20 May 2017).

54. The amount of angel investment was US\$300,000. In October 2014, the company received an additional US\$800,000 from its angel investors.

55. The company has not disclosed the exact amount to the public.

56. The "winter for venture capital" in late 2015 and early 2016 marked the end of the O2O boom. Most of the $\mathrm{O} 2 \mathrm{O}$ startups that had appeared in the previous two years did not survive. See Yue Wang, "Why O2O Leads Chinese Startups' Boom and Bust Cycle," Forbes, 21 April 2016, https://www.forbes.com/sites/ywang/2016/04/21/o2o-leads-chinese-startups-boom-and-bustcycle/\#4ad9ea827858 (accessed 20 May 2017); Wei Ling, "Ruqin de xiaoxi yijing bei zhengshi" (The news of invasion has been confirmed), Esquire, 11 December 2015, http://xw.qq.com/ c/dy/1168/20151211A02ZEF00 (accessed 20 May 2017). 
who are associated with the platform have spoken highly of it. Lin Wanrui, (57) a therapist who used to have a small private practice while keeping a full-time job as a university lecturer, described it as "dramatically useful." She joined the platform in late 2014-a relatively early stage in its history-and when she reminisced about her experiences during a conversation we had in the summer of 2016, she said:

Jiandan xinli can accelerate the process of building a full-blown private practice. In Beijing, a well-trained therapist may need two years or even longer to obtain a satisfactory clientele-roughly equivalent to a workload of 15-20 sessions per week-if she relies on word of mouth and peer referrals. However, with the help of this platform, you can reach this level much more quickly. In my case, it took less than half a year-it could have been even faster if I wanted, since the platform seemed to have more clients than its therapists could handle. ${ }^{(58)}$

Many of the therapists I knew reported that the platform helped them to acquire not just any clients but those who were especially suitable for therapy. Meng Xiao-dong, who was among the first batch of some 20 therapists on the platform, noted that the clients gained through it were good to work with, as she told me in the summer of 2015 :

I had been seeing clients in private practice for a few years before joining Jiandan xinli, so I can clearly see the special characteristics that make for good clients. They are young; almost all of them belong to the post-80s generation. They are either in the early phase of their professional careers or are still in graduate school or college. They mostly know some psychology and are capable of articulating their feelings. Mental illness is usually not the reason for their consultations. What they want is to understand themselves better.You know, these are the kind of people who read Jian Lili. (59)

Meng's impression was supported by the survey released at the press conference mentioned at the beginning of the article ${ }^{(60)}$. Among the clients who received therapy through the platform, $61.11 \%$ were $25-35$ years of age, while $21.88 \%$ were $18-25$. More than half $(55.7 \%)$ of them had a college degree, and $21.1 \%$ had a Master's degree. The most common occupation was student, followed by IT/communications/Internet, finance, and culture/media/entertainment.

Another advantage of the platform concerned its nationwide network and the uneven state of development in China. Some of my informants told me that as therapists who lived and worked in Beijing - the heart of the psycho-boom and one of the nation's most economically advanced citiesthey could easily attract clients residing in smaller or less affluent cities where finding a reliable therapist was much more difficult. As could be expected, therapy had to be conducted online under such circumstances, an arrangement that had become increasingly common in China. ${ }^{(61)}$

In addition to making connections between the two parties to therapy, the platform is also highly regarded in respect of its stringent standards, which in turn enhance the professional status of its affiliated therapists. My informants constantly compared it with the Registry System under the Chinese Psychological Society, the rigorous registration criteria and code of ethics of which, as I noted earlier, had led the way in the professionalization project that came to prominence during the last stage of the mental health legislation. In the beginning, I was a bit puzzled by this seemingly asymmetrical juxtaposition-how could we compare an e-commerce platform or a startup company with the sub-division of a semi-official organisation that represented the academic discipline of psychology under the corporatist framework (Unger and Chan 1995)? However, my informants indicated that they saw both as institutions running highly-acclaimed certifications that controlled entry not only to the respective systems but also to the profession in the making. In fact, Jiandan xinli used the term "accreditation" (renzheng 认证), which implied some formal authority, to denote its system of assessment. A therapist who passed the evaluation would earn the title of "Jiandan xinli-accredited," which had become a rather prestigious qualification commensurate with membership of the Registry System.

While most of my informants agreed upon the high calibre of both institutions, they tended to complain about the Registry System - if they were its members - or to express hesitation over whether it was worth joining. There seemed to be a consensus that one could not have immediate or practical gains from the Registry System because, despite its fame and authority within the field, it was mostly unknown to the general public. Furthermore, over the years it had made limited efforts to promote its publicity, let alone addressing the daunting task of creating an infrastructure comparable to the sleekly designed e-commerce platform of Jiandan xinli. Chen Fang, who once held an administrative position in the Registry System and was a good friend of Li Zhen, put it this way:

I do feel that Jiandan xinli is an upgraded version of the Registry System. It serves the basic function of accreditation well. And it does a lot beyond that to help therapists get clients. The e-commerce platform, the daily feeds on social media, and many other efforts-all these, needless to say, require a lot of money and staff. I don't think the Registry System, whose administration is composed of a coterie of busy and unfunded professors, can manage even a small bit of the work. (62)

Chen's words indicated that jiandan xinli functioned like a surrogate professional association as it adequately served one of its core functions-certification. However, it performed better in other equally important domains - for example, marketing and popularisation - than the bona fide professional association thanks to the ample human and financial resources that it had acquired as a standout startup company. As Larkin (2013) indicates, infrastructure can produce social effects and mobilise affective experiences and commitments. After her initial success, Li became a most vocal advocate of professionalism, as the platform was widely considered its emblem, and she increasingly displayed an interventionist attitude, exemplified by one of the company's slogans claiming that it "not only offers

57. I use pseudonyms to protect my informants' confidentiality.

58. Interview by the author, Beijing, 20 August 2016

59. Interview by the author, Beijing, 11 July 2015.

60. Jiandan xinli, and Peking University Centre for Psychological Counselling and Psychotherapy, "2016 xinli jiankang renzhidu yu xinli zixun hangye diaocha baogao" (2016 mental health literary and the psychotherapeutic profession survey report), 29 November 2016, http://www.jiandanxinli .com/report2016 (accessed on 20 May 2017).

61. While reliable statistics do not exist, my impression over these years is that therapists in China embrace online therapy quite readily. There is not much discussion on the technical and ethical issues related to this drastic alteration of therapeutic settings.

62. Interview by the author, Beijing, 12 July 2016. 
high-quality psychotherapy services, but also holds the vision of making the field of psychotherapy better." (63)

Jiandan xinli has made a series of forays into the infrastructural domains of the therapeutic profession. To begin with, in 2016, an independent platform "Jiandan xinli Uni" (简单心理 Uni) was established. It offered a 1.5year training program aimed at filling the gap between the entry-level, exam-oriented Ministry of Labour certification and an abundance of shortterm programs that were suitable for therapists who already had some experience in practice. The company has also branded itself as a partner in academic research as it has become a mine of data, chronicling the practice patterns and outcomes of several hundred practitioners, as well as a powerful channel through which a researcher can reach specific clinical populations. The company has continued to expand its services for therapists beyond the basic task of getting clients. Several new functions have been developed, including a system of peer support and referral, a mechanism for crisis management, and a monitoring system that can record a therapist's "track record" on the platform. Last but not least, the platform has gradually been recognised by the state as an important player in mental health services. For example, in July 2015, Li was invited to give a presentation at a high-level policy conference held by the Centre for Disease Control. (64) As the founder and CEO of an e-commerce startup, she stood out among the presenters, almost all of whom held leadership positions in the country's most prestigious academic institutions or hospital units.

\section{Infrastructural uncertainty and future}

This article traces the development of Jiandan xinli, the leading e-commerce platform for psychotherapy services in China. Drawing on recent anthropological scholarship on infrastructure, I elucidate how the platform has evolved into an example of "infrastructural entrepreneurship," a business that has taken the construction of infrastructure-in this case, for the field of psychotherapy - as its primary mission. I began with the context of a "diagnostic moment" in the psycho-boom, a period in which its structural ills had become apparent due to the drafting and promulgation of the mental health legislation in China. Then I described the successive transformations of Li Zhen, the founder and CEO of the company, from an ordinary university counsellor/lecturer into an Internet personality-cum-populariser, and from that into an e-commerce entrepreneur. This was followed by a description of the main functions of the platform as a kind of digital infrastructure, paying specific attention to how the team behind it can solve the underlying weaknesses of the field and establish the platform as its muchneeded infrastructure. Showing that the platform has fulfilled this purpose adequately using ethnographic methods, I argue that it functions as a surrogate professional association that in some aspects outperforms the Registry System, the leading professional association in the field.

This case study reveals the vital role that an e-commerce platform can play in a relatively embryonic profession in the Chinese context. Since the turn of the century, mental health in China has made progress along two lines: through large-scale mental health reform, which involves strengthening the infrastructure — personnel, facilities, and training —of the public psychiatric system; ${ }^{(65)}$ and the psycho-boom, which has given rise to a training industry and a private practice scene outside the formal system. While the former is almost entirely controlled and sponsored by the state, the latter has relied heavily on private entrepreneurship, with the state playing a limited yet decisive role. Part of this role also involves infrastructure-for ex- ample, establishing the Ministry of Labour certification—but most of it is rhetorical, as evidenced by the proliferation of psychology or mental healthrelated ideas in policy directives and official discourses. This developmental model left the psycho-boom with severe weaknesses, however, which in turn have offered precious opportunities to a new wave of entrepreneurship defined by digital innovation and backed by venture capital. Jiandan xinli, one of the most successful startups in this trend, has devised an e-commerce solution to repair the infrastructural defects of the field. The platform, akin to the classic examples of material infrastructure, connect dots into a networked whole, suturing the gap between clients and practitioners. Its "accreditation," like other kinds of immaterial infrastructure-standards, classification, and protocols-has helped the platform gain considerable clout in the professionalization project, which in China, as Alford and Winston argue, tends to be actively and forcefully controlled by the state (Alford and Winston 2011).

Paradoxically, infrastructure, as Howe et al. (2016) indicate, can introduce new risks, though its purpose is usually to mitigate such elements. Seen in this light, Jiandan xinli, while alleviating the uncertainty of help-seeking and conducting private practice for clients and therapists respectively, also poses new challenges that derive from its use of new technology. The digital platform undoubtedly alters the therapeutic setting. Time and money, which, as Freud (1913) postulates, constitute the core of the therapeutic frame, are processed by the platform in an impersonal way; a client can reserve or cancel a session online without making meaningful contact with the therapist. Similarly, as the client must complete the e-payment while making an appointment, the therapist loses the chance to observe how the fee is handed over. The platform has a customer support system through which the client can lodge a complaint to the administration; this benevolent mechanism, however, can be exploited by the client to avoid discussing problems with the therapist first hand. These issues may seem trivial, but they really matter, especially to those who adopt a psychoanalytic standpoint and insist on observing the conventions. Faced with these challenges, Li has engaged in an extended discussion with some senior therapists in China and abroad. These efforts recently coalesced into the platform's addition of a formal mechanism in the shape of an independent "professional committee" (zhuanye weiyuan hui 专业委员会)—which includes a number of highly-regarded experts-as a consultancy body for Li and the platform's members. It seems to me that Jiandan xinli, situated at the forefront of emental health services, is on its way to developing ethical principles pertinent to the digital environment-another crucial step in professionalization. However, the state may be an even more potent source of uncertainty in terms of Jiandan xinli's prospects. The psycho-boom in China is approaching another turning point - after the Ministry of Labour certification, Wenchuan earthquake, and the mental health legislation—as a number of important policies have begun to be revealed. At the National Health Conference (Quanguo weisheng yu jiankang dahui 全国卫生与健康大会) held in August 2016, President Xi Jinping pledged to promote various aspects of psychology, including basic research, popularisation, and professional services. In January 2017, the Commission of Health and Family Planning, along with 21 other Ministries, released the Opinions on strengthening psychological health ser-

63. See http://jdxlfile.b0.upaiyun.com/uploads/36add818f0964918a565aee766e78274.pdf (accessed on 10 October 2017) for the company's official introductory text.

64. This conference pertained to the new mental health reform; some of its policies were announced in 2016 and 2017.

65. See Baum (2017) and Pearson (2014). 
vices (guanyu jiaqiang xinli jiankang fuwu de zhidao yijian 关于加强心理健 康服务的指导意见). ${ }^{(66)}$ It vowed to build up an extensive system of psychological health services that incorporated the private practitioners that had proliferated since the early 2000s. Professionalization was another central theme; its recommendations included building a cross-disciplinary system of accreditation and facilitating the self-regulation of professional organisations. In September 2017, people involved with the psycho-boom were shocked by the removal of "psychological counsellors" from the National Vocational Qualifications (guojia zhiye zige 国家职业资格), meaning that the certificationby now about 1.1 million people have attained it—will soon vanish.

The psycho-boom is arriving at another "infrastructural moment." The Ministry of Labour certification will soon be gone, leaving the future of the training industry in doubt. Private practice as a career has become more feasible thanks to Jiandan xinli and other concurrent developments. However, it is still unclear how the state is going to implement its latest policies. Will the state set up a licensing system or will it assign the duty to certain professional associations? Which organisation(s) will be chosen by the state? How much authority will be granted? Will the state become more involved with the private mental health services sector? These are some of the issues whose consequences will seriously impact the fate of Jiandan xinli. As a startup company, it still faces the challenge of meeting growth expectations and raising more venture capital investment. The infrastructural future of the psycho-boom and the role Jiandan xinli will play in it remain to be seen.

\section{Hsuan-Ying Huang is Assistant Professor, Department of Anthropology, Chinese University of Hong Kong.}

Room 322, New Asia Humanities Building, The Chinese University of Hong Kong, Shatin, N.T. Hong Kong (hsuan-ying.huang@cuhk.edu.hk).

\section{Manuscript received on 22 June 2017. Accepted on 23 October 2017.}

66. The Commission of Health and Family Planning et al., "Guanyu jiaqiang xinli jiankang fuwu de zhidao yijian" (Opinions on strengthening psychological health services), 19 January 2017, http://www.nhfpc.gov.cn/jkj/s5888/201701/6a5193c6a8c544e59735389f31c971d5.shtml (accessed on 30 March 2017).

\section{REFERENCES}

ALFORD, William P., and Kenneth WINSTON. 2011. "Introduction." In William p. Alford, Kenneth Winston, and William C. Kirby (eds.), Prospects for the Professions in China. London and New York: Routledge. 1-21.

ANAND, Nikhil. 2011. "Pressure: The PoliTechnics of Water Supply in Mumbai." Cultural Anthropology 26(4): 542-564.

BAUM, Emily. 2017. "Chinese Psychiatric Welfare in Historical Perspective." In Beatriz Carrillo, Johanna Hood, and Paul Kadetz (eds.), Handbook of Welfare in China. London: Edward Elgar Publishing. 64-78.

BOWKER, Geoffrey C., and Susan Leigh STAR. 1999. Sorting Things Out: Classification and Its Consequences. Cambridge, MA: The MIT Press.

BURNHAM, John C. 1987. How Superstition Won and Science Lost: Popularizing Science and Health in the United States. New Brunswick: Rutgers University Press.

ELFENBEIN, Timothy. 2014. "Cultural Anthropology and the Infrastructure of Publishing." Cultural Anthropology 29(2): 288-303.

FORTUN, Kim, and Mike FORTUN. 2015. "An Infrastructural Moment in the Human Sciences." Cultural Anthropology 30(3): 359-367.

FREUD, Sigmund. 1913. "On Beginning the Treatment." In James Strachey (ed.), The Standard Edition of the Complete Psychological Works of Sigmund Freud, Volume XII (1911-1913). London: Hogarth Press. 121-144.

HANSEN, Mette Halskov, and Rune SVARVERUD (eds.). 2010. iChina: The Rise of the Individual in Modern Chinese Society. Copenhagen: NIAS Press.

HARVEY, Penny, and Hannah KNOX. 2015. Roads: An Anthropology of Infrastructure and Expertise. Ithaca, NY; London: Cornell University Press.

HIZI, Gil. 2016. "Evading Chronicity: Paradoxes in Counseling Psychology in Contemporary China." Asian Anthropology 15(1): 68-81.

HIZI, Gil. 2017. 'Developmental' Therapy for a 'Modernised' Society: The Sociopolitical Meanings of Psychology in Urban China." China: An International Journal 15(2): 98-119.

HOWE, Cymene, Jessica LOCKREM, Hannan APPEL, Edward HACKETT, Dominic BOYER, Randal HALL, Matthew SCHNEIDER-MAYERSON, Albert POPE, Akhil GUPTA, Elizabeth RODWELL, Andrea BALLESTERO, Trevor DURBIN, Farès EL-DAHDAH, Elizabeth LONG, and Cyrus MODY. 2016. "Paradoxical Infrastructures: Ruins, Retrofit, and Risk." Science, Technology, \& Human Values 41(3): 547-569.
HUANG, Hsuan-Ying. 2014. "The Emergence of the Psycho-Boom in Contemporary Urban China." In Howard Chiang (ed.), Psychiatry and Chinese History. London: Pickering \& Chatto. 183-204.

HUANG, Hsuan-Ying. 2015. "From Psychotherapy to Psycho-Boom: A Historical Overview of Psychotherapy in China." Psychoanalysis and Psychotherapy in China 1(1): 1-30.

HUANG, Hsuan-Ying. 2017. "Untamed Jianghu or Emerging Profession: Diagnosing the Psycho-Boom amid China's Mental Health Legislation." Culture, Medicine, and Psychiatry. 1-30. doi: https://doi.org/10.1007/s11013-017-9553-8.

ILLOUZ, Eva. 2008. Saving the Modern Soul:Therapy, Emotions, and the Culture of Self-Help. Berkeley and Los Angeles: University of California Press.

KENNER, Ali. 2014. "Designing Digital Infrastructure: Four Considerations for Scholarly Publishing Projects." Cultural Anthropology 29(2): 264-287.

KENNEY, Martin, and John ZYSMAN. 2016. "The Rise of the Platform Economy." Issues in Science and Technology XXXII(3): 61-69.

KIPNIS, Andrew (ed.). 2012. Chinese Modernity and the Individual Psyche. New York: Palgrave Macmillan.

KLEINMAN, Arthur, Yunxiang YAN, Jun JING, Sing LEE, Everett ZHANG, Tianshu PAN, Fei WU, and Jinhua GUO. 2011. Deep China:The Moral Life of the Person. Berkeley and Los Angeles: University of California Press.

LARKIN, Brian. 2013. "The Politics and Poetics of Infrastructure." Annual Review of Anthropology 42: 327-343.

LEVY, Robert, and Douglas HOLLAN. 1998. "Person-Centered Interviewing and Observation." In Russell H. Bernard (ed.), Handbook of Methods in Cultural Anthropology. Walnut Creek, CA: AltaMira Press. 333-364.

LI, Anthony H. F. 2016. "Whom to Trust When Sick: The Wei Zexi Incident, the Chinese Internet, and the Healthcare System in China." China Perspectives 2016(4): 79-83.

LI, Zhen (Jian Lili). 2015. Nishi yiqie de daan (You are the answer to everything, or Clorious Ruins). Beijing: CITIC Press.

LIU, Jin, Hong MA, Yan-Ling HE, Bin XIE, Yi-Feng XU, Hong-Yu TANG, Ming Li, Wei HAO, Xiang-Dong WANG, Ming-Yuan ZHANG, Chee H. NG, Margaret GODING, Julia FRASER, Helen HERRMAN, Helen F. K. CHIU, Sandra S. CHAN, Edmond CHIU, and Xin YU. 2011. "Mental Health System in China: History, Recent Service Reform and Future Challenges." World Psychiatry 10(3): 210-216. 
MAINS, Daniel. 2012. "Blackouts and Progress: Privatization, Infrastructure, and a Developmentalist State in Jimma, Ethiopia." Cultural Anthropology 27(1): 3-27.

MA, Hong. 2012. "Integration of Hospital and Community Services - the "686" Project - Is a Crucial Composition in the Reform of China's Mental Health Services." Shanghai Archives of Psychiatry 24(3): 172-174.

MA, Huateng (ed.). 2015. Hulianwang jia: guojia zhanlue xingdong luxian tu (Internet plus: national strategic action road map). Beijing: CITIC Press.

MA, Winston. 2017. China's Mobile Economy: Opportunities in the Largest and Fastest Information Consumption Boom. Chichester, West Sussex: John Wiley \& Sons Ltd.

NADER, Laura. 1972. "Up the Anthropologist: Perspectives Gained from Studying Up." In Dell Hymes (ed.), Reinventing Anthropology. New York: Pantheon Books. 284-311.

NOVOTNEY, Amy. 2017. "A Growing Wave of Online Therapy." Monitor on Psychology 48(2): 48.

PEARSON, Veronica. 2014. "The Development of Psychiatric Services in China: Christianity, Communism, and Community." In Bridie Andrews and Mary Brown Bullock (eds.), Medical Transitions in Twentieth Century China. Bloomington \& Indianapolis: Indiana University Press. 146-170.

PHILLIPS, Michael R., Jingxuan ZHANG, Qichang SHI, Zhiqiang SONG, Zhijie DING, Shutao PANG, Xianyun LI, Yalin ZHANG, and Zhiqing WANG. 2009. "Prevalence, Treatment, and Associated Disability of Mental Disorders in Four Provinces in China during 2001-05: An Epidemiological Survey." The Lancet 373(9680): 13-19.

QIAN, Mingyi, Jun GAO, Ping YAO, and Marcus Arnold RODRIGUEZ. 2009. "Professional Ethical Issues and the Development of Professional Ethical Standards in Counseling and Clinical Psychology in China." Ethics \& Behavior 19(4): 290-309.

RIEFF, Philip. 1966. The Triumph of the Therapeutic: Uses of Faith after Freud. New York: Harper \& Row.

SEO,Bo Kyeong. 2017. "Locating Care within the Nascent Infrastructure: Renal Dialysis in Thailand." Medizinethnologie: Körper, Gesundheit und Heilung in einer globalisierten Welt, 26 January . http://www.medizinethnologie.net/renal-dialysis-inthailand/ (accessed on 10 October 2017).
STAR, Susan Leigh. 1999. "The Ethnography of Infrastructure." American Behavioral Scientist 43(3): 377-391.

STONE, Brad. 2013. The Everything Store: Jeff Bezos and the Age of Amazon. New York: Little, Brown, and Company.

STREET, Alice. 2014. Biomedicine in an Unstable Place. Durham, NC: Duke University Press.

UNGER, Jonathan, and Anita CHAN. 1995. "China, Corporatism, and the East Asian Model." The Australian Journal of Chinese Affairs (33): 29-53.

XIANG, Biao, and Johan LINDQUIST. 2014. "Migration Infrastructure." International Migration Review 48: S122-S148.

YANG, Jie. 2015. Unknotting the Heart: Unemployment and Therapeutic Governance in China. Ithaca; London: IPR Press, an imprint of Cornell University Press.

ZHANG, Li. 2014. "Bentuhua: Culturing Psychotherapy in Postsocialist China." Culture, Medicine and Psychiatry 38(2): 283-305.

ZHANG, Li. 2017a. "The Rise of Therapeutic Governing in Postsocialist China." Medical Anthropology 36(1): 6-18.

ZHANG, Li. 2017b. "Cultivating the Therapeutic Self in China." Medical Anthropology. doi: http://dx.doi.org/10.1080/01459740.2017.1317769.

ZHANG, Lili, Peng YANG, Migyi QIAN, Hong CHEN, Jie ZHONG, Ping YAO, Kaiwen XU, Chunli Yl, Zhifeng ZHANG, and Yiping WANG. 2010. "Butong zhuanye beijing xinli zhiliao yu zixun zhuanye renyuan de linchuang gongzuo xianzhuang" (Current clinical practice in psychotherapy and counselling by personnel with different professional backgrounds). Chinese Mental Health Journal 24(12): 948-953.

ZHANG, Weiyu. 2016. The Internet and New Social Formation in China: Fandom Publics in the Making. Abingdon, Oxon: Routledge.

ZHONG, Jie, Mingyi QIAN, Ping YAO, and Kevin XU. 2008. "Accountability in Professional Psychology: The Improvement in Mainland China." In Judy E. Hall and Elizabeth M. Altmaier (eds.), Global Promise: Quality Assurance and Accountability in Professional Psychology. New York: Oxford University Press. 190-195. 